blood, using the Kahn and complement fixation tests. He finds that, in these animals, the reaction of the aqueous is not parallel to that of the blood and that it may remain persistently negative, even when there are active syphilitic lesions present in the eye. $\mathrm{He}$ concludes that the uveal capillary system offers a barrier which prevents the passage of specific anti-bodies from the blood to the aqueous.

\title{
CORRESPONDENCE
}

\section{INTRA-OCULAR DRAINAGE}

To the Editors of The British Journal of Ophthalmology.

SIRS,-While polenic articles are to be deprecated in every sense, I think that a misinterpretation in Mr. Ridley's paper in the February issue of this Journal ought to be cleared up. $\mathrm{He}$ interprets my writings as indicating that " not until a chamber pressure of $40 \mathrm{~mm}$. Hg is reached "does the exit venous pressure fall below the intra-ocular pressure $(39 \mathrm{~mm}$. $\mathrm{Hg})$. It is true that in the protocol of the one experiment referred to, when the intraocular pressure was $40 \mathrm{~mm}$. $\mathrm{Hg}$ the exit venous pressure was $39 \mathrm{~mm}$. $\mathrm{Hg}$, but this is one illustration only of the general condition that "whenever the chamber pressure is raised" this relationship occurs. Normally the venous pressure is 1.5 to 2.0 $\mathrm{mm} . \mathrm{Hg}$ above the intra-ocular pressure: if the intra-ocular pressure is raised by 1.5 to $2.0 \mathrm{~mm}$. $\mathrm{Hg}$ it becomes equal to the venous pressure; if it is raised further than this, it exceeds it. This is simply a statement of facts as found in experimental conditions; moreover it can be frequently demonstrated clinically (as has been pointed out by Thomson Henderson) by observing the compression of the veins at the disc by exerting the slightest finger-pressure on the globe. In the type of experiment described by me in your issue of December last and discussed in Mr. Ridley's paper, when the intra-ocular pressure is raised by $2.0 \mathrm{~mm} . \mathrm{Hg}$, methylene blue flows into the episcleral veins in $1 \frac{1}{2}$ minutes, and there is no trace of the dye in the conjunctival sac which I can discover after observations lasting considerably over one hour. Moreover, examination of eyes similarly injected, not only by myself but by a very large number of writers in Germany, France, and America and this country (References, see my Monograph on the "Nature of the Intra-Ocular Fluids," 1927) have conclusively shown that the path of drainage is (at any rate largely) via the trabeculae of the angle of the anterior 
chamber. This experiment to my mind still shows very clearly that in its circulation the intra-ocular fluid (which I have never considered to be stagnant, but to circulate owing to factors other than those governing the process of its formation (see this Journal, Vol. XI, p. 388 ; Jl. of Physiol., Vol. LXXI, p. 1, and elsewhere) finds an exit more readily by way of the canal of Schlemm than through the corneal tissues into the conjunctival sac.

Yours etc.,

W. S. Duke-Elder.

LONDON,

February 7, 1931.

\section{TREPHINING FOR GLAUCOMA}

To the Editors of The British Journal of Ophthalmology.

SIRS,-In his article on page 34 of your January number, $\mathrm{Mr}$. George Brookes makes the following statement:- "Elliot (Glaucoma, page 536) instructs that the flap be made as thick as possible at its base. This in my opinion is wrong. A plane of tissue dissected by a metal instrument is more likely to heal down again ; it is artificial, and resented by Nature."

I cannot find the instruction to which he refers on that page though there are four other references in the index to "Flap to be made thick." I am, therefore, a little uncertain of his exact meaning. There is, however, one point which I consider, and always have considered, essential to the success of the operation; it is that the flap should be made thick in order to protect the eye from the possible ingress of infection from without. The stress I lay on this is clear from the fact that I devoted nearly seven pages of my book to the subject, pages 535 to 541 , besides making a number of further references to it on other pages. I will not, therefore, weary your readers by going over the ground again, but as there appears to be still a possibility of a misunderstanding, I would like, in the interests of the many surgeons who are using the method to-day, to lay stress on two points :-

(1) The technique I have advocated rests throughout on following the normal planes of the conjunctival and corneal structures and in avoiding cutting across them.

(2) When I have spoken of making the base of the flap thick I have meant-and have endeavoured to make my meaning clear-that as the cornea is approached, the whole of the episcleral tissue should be taken up and the flap should be continued along the 